\title{
Application of ATR-FTIR Spectroscopy and Decreased Proteins As Parameter of Negative Neonatal Outcomes in Women With Gestational Diabetes Mellitus
}

Emanuelly Bernardes-Oliveira ( $\nabla$ bio_natalm@yahoo.com.br)

Federal University of Rio Grande do Norte

Daniel Lucas Dantas de Freitas

Federal University of Rio Grande do Norte

Ricardo Ney Cobucci

Federal University of Rio Grande do Norte

Maria da Conceição Mesquita Cornetta

Federal University of Rio Grande do Norte

Juliana Dantas de Araújo Santos Camargo

Federal University of Rio Grande do Norte

Kássio Michell Gomes de Lima

Federal University of Rio Grande do Norte

Janaina Cristiana de Oliveira Crispim

Federal University of Rio Grande do Norte

\section{Research Article}

Keywords: Macrosomia, Gestational diabetes mellitus, ATR-FTIR, GA-LDA, Proteins

Posted Date: January 26th, 2021

DOI: https://doi.org/10.21203/rs.3.rs-152745/v1

License: (c) (1) This work is licensed under a Creative Commons Attribution 4.0 International License. Read Full License 


\section{Abstract}

In this study, we found for the first time that macrosomal newborns were associated with lower protein density when mothers with GDM were analyzed by infrared ATR-FTIR (Attenuated Total Reflection Fourier Transform) spectroscopy, and the Genetic Algorithm (GA) mathematical model associated with Linear Discriminant Analysis (LDA). This is a case-control study, comprised of a total of 49 newborns from mothers with GDM compared with 45 newborns from mothers without GDM. The evaluated neonatal outcomes were: type of delivery, prematurity, weight in relation to gestational age, apgar, macrosomia, and head/chest perimeter. Furthermore, we correlated the presence of these neonatal adverse effects with the density of proteins in GDM. The neonatal outcomes observed in newborns of mothers with GDM showed prematurity $(p=0.018)$, minimum head circumference $(p=0.027)$, abdominal circumference $(p$ $<0.01)$ and macrosomia $(p<0.01)$ when compared to newborns of mothers without GDM. Prematurity and macrosomia occurred with greater significance among pregnant women diagnosed with gestational diabetes $(p<0.05)$. There was a correlation between macrosomal newborns and low protein density confirmed by ATR-FTIR (GA-LDA) in diabetic pregnant women. On the other hand, macrosomal newborns of mothers with GDM were correlated with women who showed lower density of protein when analyzed by ATR-FTIR (GA-LDA). In this study, we observed that macrosomia was associated with low protein density of a mother with GDM. The approach described here, can be useful for the identification and exploration of macrosomia inunder various pathophysiological conditions of maternal GDM.

\section{Introduction}

Newborns of women with Gestational Diabetes Mellitus (GDM) are more likely to have complications at birth. Among the most common complications that occur in these in newborns are macrosomia, shoulder dystocia at birth ${ }^{1}$, congenital heart defects ${ }^{2}$, congenital malformations ${ }^{3}$, hyperbilirubinemia, respiratory distress $^{4,5}$ and stillbirth ${ }^{6}$.

Recent studies show that the mother's obesity, advanced age ${ }^{7}$, triglyceride ${ }^{8}$, and hypertension and chronic stress can be associated with increased fetal cortisol promoting insulin resistance ${ }^{9}$. Currently, the mechanism of GDM pathophysiology is not completely understood, principally how it harms newborns. It is believed that GDM associated with other maternal negative factors is directly related to fetal macrosomia. However, it is known that maternal hyperglycemia contributes to transplacental transfer of glucose to the fetus, stimulating fetal pancreatic $\beta$ cells to release insulin, resulting in macrosomal growth $^{10,11}$, with an increase in fat deposition in the abdominal circumference ${ }^{12}$ and loss of maternal and infant well-being during delivery. There are also the possible later sequels, such as seizure activity, neurologic damage, developmental delay, personality disorders, obesity and type 2 diabetes $^{13}$.

Currently, there is great clinical concern regarding these outcomes that are unfavorable in the development and in birth of the fetus of women with GDM, generating complications in the last quarter of pregnancy and in most cases these can occur in anaccelerated manner, especially in relation to macrosomal growth. However, methods of macrosomia prediction are not yet well established, and this 
limits obstetric decisions ${ }^{14}$. For this reason, it is important to discover new biomarkers to predict adverse neonatal outcomes of newborns from mothers with GDM.

Fourier Transform Infrared spectroscopy (FTIR), which together with Attenuated Total Reflectance (ATR), is an important technique in the biomedical area, and its use in biological studies is promising, with a capacity to detect and quantify biomolecules present in cells and tissues altered by different diseases $^{15,16}$.

In a previous study, our group found an increase in blood plasma protein density identified by ATR-FTIR in women with $\mathrm{GDM}^{17}$. In this study, our aim was to correlate the adverse neonatal outcomes according to the protein density of mothers with GDM.

\section{Methods}

\subsection{Study Design}

This is a case-control study, including 49 newborns from mothers with GDM in a reference maternal institution in Rio Grande do Norte (UFRN), Brazil, between January and October 2018. All anthropometric measurements including weight, length, and head/chest perimeter of the newborns were analysed and based shortly after birth, and then categorized according to the WHO.

The results of the outcomes of the newborns were also analysed and based on delivery and complication: Type of delivery (born via vaginal or lower segment cesarean section), gestational age by prematurity ( $<37$ weeks), respiratory distress, apgar in the 1st and 5th minute, intensive therapy, jaundice, malformation, neonatal blood hypoglycemia and macrosomia (large for gestational age, defined as birth weight $>4000 \mathrm{~g}$ ). GDM was diagnosed according to the guidelines of the American Diabetes Association $(A D A)^{18}$, with blood glucose changes between $\geq 92 \mathrm{mg} / \mathrm{dL}$ and $<126 \mathrm{mg} / \mathrm{dL}$ during prenatal care.

This study excluded: Stillbirth (defined as pregnancy loss $>24$ weeks gestation), spontaneous abortion (defined as pregnancy loss $\leq 23$ weeks gestation), termination of pregnancy, loss of follow-up or transfer of care to another center before the childbirth.

The study was approved by the Ethics Committee of UFRN (CAAE 73305717.2.0000.5292). The institutions in which the data collection process was carried out gave their endorsement and authorization for the review of data sources. An informed consent form was signed by all pregnant women prior to data collection. All procedures were performed in compliance with the Declaration of Helsinki.

\subsection{Control group}

The control group included 45 newborns of mothers without GDM (blood glucose $<92 \mathrm{mg} / \mathrm{dL}$ post screening OGTT at 24 - 28 weeks) and no other comorbidities. 
The venous blood of the mothers when they were pregnant was collected and centrifuged for the separation of blood plasma. ATR-FTIR was used to analyze the absorbance biomolecules present in the blood plasma of pregnant women with GDM and their correlation with adverse neonatal outcomes. In order to obtain absorption by the spectrophotometer the biological range of the spectral region analyzed was from $1,800 \mathrm{~cm}^{-1}$ to $900 \mathrm{~cm}^{-1}$. Subsequently, biomolecule absorption was analyzed by the mathematical model Genetic Algorithm (GA) associated with Linear Discriminant Analysis (LDA) and compared with plasma samples from mothers without GDM, as described by Paraskevaidi et al., (2017) ${ }^{19}$ and Neves et al., $(2016)^{20}$, with some modifications.

\section{Statistical Analysis}

The Shapiro-Wilk normality test was applied to verify the adherence of continuous variables to the normal distribution. Descriptive analysis of the variables that obtained adherence to the normal distribution was performed by the mean and standard deviation (Mean $\pm \mathrm{SD}$ ). For variables that did not present normal distribution in either group, the median and the 25th and 75th percentiles were used. For categorical variables, the analysis was performed using absolute and relative frequencies. Student's t-test for independent samples was applied for continuous variables that presented normality. The Mann-Whitney nonparametric test was used to compare the differences between the distributions of variables that did not show normality. The chi-square test was used to analyze the association between type of delivery and categorical variables. In situations where the table cells presented expected frequencies below five, Fisher's exact test was applied. A significance level of $5 \%$ was adopted for all analysis. The software used for the analysis was the Statistical Package for the Social Sciences (Chicago, USA), version 22.0.

\section{Results}

Table 1 shows the prevalence of adverse neonatal outcomes of the 94 newborns, 49 born to a mother with GDM and 45 born to a mother without GDM. It is possible to verify that the newborn of a mother with GDM was statistically different from the newborn of a mother without GDM, in relation to the gestational age in weeks $(p<0.01)$, which corroborates the findings of prematurity found in this same group $(p=$ 0.018). When the anthropometric characteristics of the newborns were compared, the mean weight to length ratio for the newborns exposed and not exposed to GDM showed no statistical difference. Whereas with the measurements in relation to waist circumference $(p<0.01)$ and head circumference $(p$ $=0.027$ ), the group of newborns from mothers with GDM was statistically different when compared to the group of newborns from mothers without GDM. In this study, it was also observed that the newborns from mothers with GDM were macrosomal $(p<0.01)$. However, there were no statistical differences among newborns of mothers with or without GDM, in relation to type of delivery, sex of newborns, birth length, apgar in the 1st and 5th minute, neonatal hypoglycemia, jaundice, intensive therapy, malformation and respiratory distress. 
Table 1

Prevalence of adverse neonatal outcomes in newborns of mothers with and without GDM.

\begin{tabular}{|c|c|c|c|c|}
\hline Variables & $\begin{array}{l}\text { Newborns of mothers with GDM } \\
(\mathrm{N}=49)\end{array}$ & $\begin{array}{l}\text { Newborns of } \\
\text { mothers } \\
\text { without GDM ( } \mathrm{N} \\
=45)\end{array}$ & $\begin{array}{l}\mathrm{P} \\
\text { value }^{\mathrm{a}}\end{array}$ & Total \\
\hline \multicolumn{5}{|l|}{ Type of delivery, $n$ (\%) } \\
\hline Cesarean & $35(71.4 \%)$ & $29(64.4 \%)$ & 0.468 & $\begin{array}{l}64 \\
(68.1 \%)\end{array}$ \\
\hline Vaginal & $14(28.6 \%)$ & $16(35.6 \%)$ & & $\begin{array}{l}30 \\
(31.9 \%)\end{array}$ \\
\hline Induced labor, n (\%) & $5(10.2 \%)$ & $8(17.8 \%)$ & 0.288 & $\begin{array}{l}13 \\
(13.8 \%)\end{array}$ \\
\hline Gestational age, weeks & $37(36-38)$ & $39(38-40)$ & $\begin{array}{l}p< \\
0.01\end{array}$ & $\begin{array}{l}38(37- \\
39)\end{array}$ \\
\hline Prematurity, n (\%) & $12(24.5 \%)$ & $3(6.7 \%)$ & 0.018 & $\begin{array}{l}15 \\
(16.0 \%)\end{array}$ \\
\hline Birth length, $\mathrm{cm}$ & $49(47-51)$ & $50(48-51)$ & 0.236 & $\begin{array}{l}49(47- \\
51)\end{array}$ \\
\hline \multicolumn{5}{|l|}{ Sex, n (\%) } \\
\hline Female & $23(46.9 \%)$ & $24(53.3 \%)$ & 0.536 & $\begin{array}{l}47 \\
(50.0 \%)\end{array}$ \\
\hline Male & $26(53.1 \%)$ & $21(46.7 \%)$ & & $\begin{array}{l}47 \\
(50.0 \%)\end{array}$ \\
\hline Waist perimeter, $\mathrm{cm}$ & $32(31-34)$ & $32(30-34)$ & 0.873 & $\begin{array}{l}32(31- \\
34)\end{array}$ \\
\hline $\begin{array}{l}\text { Abdominal perimeter, } \\
\mathrm{cm}\end{array}$ & $32(31-34)$ & $31(30-32)$ & $\begin{array}{l}p< \\
0.01\end{array}$ & $\begin{array}{l}32(31- \\
33)\end{array}$ \\
\hline \multicolumn{5}{|l|}{ Head perimeter, $\mathrm{n}(\%)$} \\
\hline Minimum & $5(10.5 \%)$ & $4(8.9 \%)$ & 0.027 & $9(9.6 \%)$ \\
\hline
\end{tabular}

aSignificance of difference between groups by Mann-Whitney $U$ test (continuous variables) or Pearson's or Fisher's chi-square test (categorical variables). 4 (5.2\%)

Continuous data are expressed as medians and 25th and 75th percentiles.

Categorical data are expressed as absolute (n) and relative (\%) frequency.

Values in bold indicate significance at $p<0.05$

Abbreviations: GDM, Gestational Diabetes Mellitus; 


\begin{tabular}{|c|c|c|c|c|}
\hline Variables & $\begin{array}{l}\text { Newborns of mothers with GDM } \\
(\mathrm{N}=49)\end{array}$ & $\begin{array}{l}\text { Newborns of } \\
\text { mothers } \\
\text { without GDM (N } \\
=45)\end{array}$ & $\begin{array}{l}\mathrm{P} \\
\text { value }^{\mathrm{a}}\end{array}$ & Total \\
\hline Medium & $22(44.9 \%)$ & $32(71.1 \%)$ & & $\begin{array}{l}54 \\
(57.4 \%)\end{array}$ \\
\hline Maximum & $22(44.9 \%)$ & $9(20.0 \%)$ & & $\begin{array}{l}31 \\
(33.0 \%)\end{array}$ \\
\hline $\begin{array}{l}\text { Apgar in the } 1 \text { th minute, } \\
\text { points }\end{array}$ & $9(8-9)$ & $9(8-9)$ & 0.512 & $9(8-9)$ \\
\hline $\begin{array}{l}\text { Apgar in the 5th minute, } \\
\text { points }\end{array}$ & $9(9-9)$ & $9(9-9)$ & 0.922 & $9(9-9)$ \\
\hline \multicolumn{5}{|l|}{$\begin{array}{l}\text { Neonatal outcomes, } \mathrm{n} \\
(\%)\end{array}$} \\
\hline Macrosomia & $14(28.6 \%)$ & $1(2.2 \%)$ & $\begin{array}{l}p< \\
0.01\end{array}$ & $\begin{array}{l}15 \\
(16.0 \%)\end{array}$ \\
\hline Neonatal hypoglycemia & $2(4.2 \%)$ & $2(6.9 \%)$ & 0.629 & $4(5.2 \%)$ \\
\hline Jaundice & $15(30.6 \%)$ & $11(24.4 \%)$ & 0.504 & $\begin{array}{l}26 \\
(27.7 \%)\end{array}$ \\
\hline Intensive therapy & $6(12.2 \%)$ & $3(6.7 \%)$ & 0.490 & $9(9.6 \%)$ \\
\hline Malformation & $2(4.1 \%)$ & $2(4.4 \%)$ & 1.000 & $4(4.3 \%)$ \\
\hline Respiratory distress & $11(22.4 \%)$ & $11(24.4 \%)$ & 0.819 & $\begin{array}{l}22 \\
(23.4 \%)\end{array}$ \\
\hline \multicolumn{5}{|c|}{$\begin{array}{l}\text { aSignificance of difference between groups by Mann-Whitney U test (continuous variables) or } \\
\text { Pearson's or Fisher's chi-square test (categorical variables). } 4 \text { (5.2\%) }\end{array}$} \\
\hline \multicolumn{5}{|c|}{ Continuous data are expressed as medians and 25 th and 75 th percentiles. } \\
\hline \multicolumn{5}{|c|}{ Categorical data are expressed as absolute (n) and relative (\%) frequency. } \\
\hline \multicolumn{5}{|c|}{ Values in bold indicate significance at $p<0.05$} \\
\hline Abbreviations: GDM, Gest & ional Diabetes Mellitus; & & & \\
\hline
\end{tabular}

This study demonstrates the potential of ATR-FTIR techniques and multivariate models of GA-LDA as possible methodologies to recognize which biomolecules are possibly involved in the neonatal outcomes in women with GDM. We used the ATR-FTIR technique to analyze the distribution of the absorbance of biomolecules such as lipids, proteins, carbohydrates and nucleic acids (Fig. 1) in mothers with and without GDM. Interestingly, when we evaluated the presence of biomolecules in relation to adverse neonatal effects, we observed that macrosomal newborns were associated with lower protein density in the regions of $1.587 \mathrm{~cm}^{-1}(p=0.049)$ and $1.589 \mathrm{~cm}^{-1}(p=0.043)$ in GDM (Fig. 2). 


\section{Discussion}

There are few studies that relate macrosomia and the search for new biomarkers that will predict the possible mechanism of GDM and its correlation with adverse neonatal outcomes. To our knowledge, our group was first that used ATR-FTIR and the mathematical model coupled to the GA-LDA algorithm to analyze the blood plasma that was collected from women with GDM during pregnancy. With this methodology we observed a lower density of protein biomolecules with the presence of macrosomia. Other studies have found similar results regarding the density of certain proteins in the placenta. In fact, when phosphorylated Adenosine monophosphate-activated protein kinase (p-AMPKa), phosphorylated Acetyl CoA carboxylase ( $\mathrm{p}-\mathrm{ACC}$ ) and proteins of Caveolin-1 (Cav-1) were evaluated, all showed a decrease and were associated with the presence of macrosomia in newborns of mothers with GDM. On the other hand, the glucose transporter-1 (GLUT-1) showed an increase when associated with the presence of macrosomia in newborns of mothers with GDM. These proteins are known to be present in the placenta and are known to be a glucose transporter ${ }^{21}$. However, the exact role of these proteins remains unclear, especially in the involvement of macrosomia.

Macrosomia is directly or indirectly associated with impairment of pancreatic $\beta$ cell function, sensitivity to insulin and high maternal blood glucose ${ }^{12,22,23}$. From our findings we observed a larger significance of macrosomal in newborns from mothers with GDM. This finding is in agreement with the literature, where the prelavence is approximately $15-45 \% 24$. In addition, other studies have shown that the disharmony of maternal homeostasis via chronic stress promotes an increase in cortisol and glucose in the fetus, especially in early pregnancy, triggering insulin resistance, weight gain and fetal prematurity ${ }^{9}$. In fact, we also found a significant increase in the number of premature babies associated with GDM.

Another gestational factor that can contribute to worse neonatal outcomes, is the increase in adipocytin secreted by the placenta, which has the role of regulating insulin secretion, inducing a compromised immune response to hyperglycemia, with an increase in pro-inflammatory cytokines such as IL-1 and IL-6, and the formation of ROS and TNF- $\mathrm{a}^{25,26}$. This whole cascade can promote maternal obesity, which is likely to influence fetal macrosomia. In a recent study conducted in Turkey, it was observed that newborns were twice as likely to be macrosomal when the mother had a change in BMl, with values $\geq 25 \mathrm{~kg} / \mathrm{m} 2$ in the pre-pregnancy phase, or with those who gained $\geq 12 \mathrm{~kg}$ during pregnancy ${ }^{27}$. This reinforces the fact that maternal obesity is causally associated with factors that promote an increase in the fetal body and contributes to adverse neonatal outcomes ${ }^{28}$. Moreover, this becomes even more serious, when the fetus is exposed to a pregnancy with GDM, which directly influences gestational development ${ }^{29,30}$. It is likely that this can be directly linked to the results by our group, in which women with GDM were more obese when compared to women without GDM. Still remaining in the context of obesity and macrosomia, during pregnancy there is an increase in leptin, resistin and visfatin, which are more expressed between the end of the first trimester and the beginning of the second trimester. The presence of these proteins constitutes an inflammatory and insulin resistant microenvironment ${ }^{25}$. Therefore, further studies are needed to identify which proteins are possibly associated with macrosomia. 


\section{Conclusion}

Pregnancy affected by GDM promotes immediate or long-term negative consequences for women and their newborns exposed to hyperglycemia, being that the gestational outcomes are not yet well understood. Therefore, there is a need for new tools that can assist in the early diagnosis of GDM, which is associated with birth outcomes that have a negative prognosis, such as prematurity, macrosomia, and increased abdominal and head circumference. This is especially when these fetal changes are caused by high-risk pregnancies, such as those generated by women with GDM. This study demonstrated that ATRFTIR spectroscopy, together with the multivariate analysis technique of GA-LDA, is the most robust model and is able to discriminate in blood plasma samples from GDM women the increase in protein biomolecules that are involved in outcomes of newborns with worse prognosis. These results suggest that biospectroscopy and chemometrics are tools that are sensitive to biochemical variations caused by GDM that harm the fetus, and are useful during prenatal care.

\section{Declarations}

\section{Acknowledgments}

The authors would like to thank the pregnant women who participated in the study, the Januário Cicco Maternity School and Divine Motherhood of Love Maternity, the Federal University of Rio Grande do Norte, the Post-Graduate Program in Technological Development and Innovation in Medicines (PPGDITM/UFRN), the Post-Graduate Program in Chemistry (PPGQ/UFRN), and the Laboratory of Biological Chemistry and Chemometrics of the Institute of Chemistry. Emanuelly Bernardes-Oliveira and Daniel Lucas Dantas de Freitas, would like to thank CAPES - Brazil for their research grants.

\section{Author Contributions Statement}

E.M-O and D.L.D.F were responsible for acquiring the spectral data. E.M-O and J.C.O.C were responsible for writing the first draft of the manuscript. D.L.D.F. was responsible for the construction of the chemometric models and multivariate analysis. K.M.G.L, R.N.C, M.C.M.C and J.D.A.S.C provided chemometric support and finalised the manuscript. J.C.O.C. and K.M.G.L. designed the experiments, supervised the project and revised the manuscript.

\section{References}

1. Liu J, Song G, Meng T, et al. Weight retention at six weeks postpartum and the risk of gestational diabetes mellitus in a second pregnancy. BMC Pregnancy Childbirth, 19(1):272. doi:10.1186/s12884019-2423-3 (2019).

2. Guang-Ran Yang, Timothy D. Dye, Dongmei Li. Effects of pre-gestational diabetes mellitus and gestational diabetes mellitus on macrosomia and birth defects in Upstate New York, Diabetes Research and Clinical Practice. Volume 155, 107811, org/10.1016/j.diabres.2019.107811 (2019). 
3. Nasri $\mathrm{HZ}$, Houde $\mathrm{Ng} \mathrm{K}$, Westgate MN, et al. Malformations among infants of mothers with insulindependent diabetes: Is there a recognizable pattern of abnormalities? Birth Defects Res. 110(2):108113. doi: 10.1002/bdr2.1155 (2018).

4. Li-Zhen L, Yun X, Xiao-Dong Z, et al. Evaluation of guidelines on the screening and diagnosis of gestational diabetes mellitus: systematic review. BMJ Open. 9(5):e023014. doi:10.1136/bmjopen2018-023014 (2019).

5. Donovan BM, Breheny PJ, Robinson JG, et al. Development and validation of a clinical model for preconception and early pregnancy risk prediction of gestational diabetes mellitus in nulliparous women. PLoS One. 14(4):e0215173. Published 2019 Apr 12. doi:10.1371/journal.pone.0215173 (2019).

6. Stacey $T$, Tennant $P$, McCowan $L$, et al. Gestational diabetes and the risk of late stillbirth: a casecontrol study from England, UK. BJOG. 126(8):973-982. doi: 10.1111/1471-0528.15659. Epub 2019 Mar 19. PMID: 30891907 (2019).

7. Kim W, Park SK, Kim YL. Gestational diabetes mellitus diagnosed at 24 to 28 weeks of gestation in older and obese Women: Is it too late? PLoS One. 14(12):e0225955. doi:10.1371/journal.pone.0225955 (2019).

8. Samsuddin S, Arumugam PA, Amin MS Md, et al. Maternal lipids are associated with newborn adiposity, independent of GDM status, obesity and insulin resistance: a prospective observational cohort study. BJOG. 127(4):490-499. doi: 10.1111/1471-0528.16031 (2020).

9. Valsamakis G, Papatheodorou D, Chalarakis N, et al. Maternal chronic stress correlates with serum levels of cortisol, glucose and C-peptide in the fetus, and maternal non chronic stress with fetal growth. Psychoneuroendocrinology. 25;114:104591. doi: 10.1016/j.psyneuen.2020.104591 (2020).

10. Agha-Jaffar R, Oliver N, Johnston D, Robinson S. Gestational diabetes mellitus: does an effective prevention strategy exist? Nat Rev Endocrinol, 12(9):533-546. doi.org/10.1038/nrendo.2016.88 (2016).

11. Stewart A, Malhotra A. Gestational diabetes and the neonate: challenges and solutions. Research and Reports in Neonatology, 5:31-39. doi.org/10.2147/RRN.S30971 (2015).

12. Mourad M, Friedman AM, Ajemian B, Ferleger S, Ananth CV, Zork N. Fetal growth velocity in diabetics and the risk for shoulder dystocia: a case-control study. J Matern Fetal Neonatal Med, 12:1-5. doi: 10.1080/14767058.2019.1651838 (2019).

13. Kc K, Shakya S, Zhang H. Gestational diabetes mellitus and macrosomia: a literature review. Ann Nutr Metab, 66 Suppl 2:14-20. doi: 10.1159/000371628 (2015). 
14. Nahavandi S, Seah JM, Shub A, Houlihan C, Ekinci El. Biomarkers for Macrosomia Prediction in Pregnancies Affected by Diabetes. Front Endocrinol (Lausanne), 9:407. doi:10.3389/fendo.2018.00407 (2018).

15. Mitchell AL, Gajjar KB, Theophilou G, Martin FL, Martin-Hirsch PL.Martin-Hirsch. Vibrational spectroscopy of biofluids for disease screening or diagnosis: translation from the laboratory to a clinical setting. J. Biophotonics 7, No. 3-4, 153-165 doi: 10.1002/jbio.201400018 (2014).

16. Kelly JG, Trevisan J, Scott AD, Carmichael PL, et al. Biospectroscopy to metabolically profile biomolecular structure: a multistage approach linking computational analysis with biomarkers, J. Proteome Res. 10 1437-1448. org/10.1021/pr101067u (2011).

17. Bernardes-Oliveira, E, de Freitas, DLD, de Morais, CD, et al.Spectrochemical differentiation in gestational diabetes mellitus based on attenuated total reflection Fourier-transform infrared (ATRFTIR) spectroscopy and multivariate analysis. Sci Rep 10, doi.org/10.1038/s41598-020-75539-y (2020).

18. American Diabetes Association. Classifcation and diagnosis of diabetes: Standards of medical care in diabetes-2018. Diabetes Care 41(Supplement 1), S13-S27. doi.org/10.2337/dc18-S002 (2018).

19. Paraskevaidi M, Morais CLM, Lima KMG, et al. Differential diagnosis of Alzheimer's disease using spectrochemical analysis of blood, Proc. Acad. Sci. U.S.A. 114, E7929-E7938. doi:10.1073/pnas.1701517114 (2017).

20. Neves ACO, Silva PP, Morais CLM, et al. ATR-FTIR and multivariate analysis as a screening tool for cervical cancer in women from northeast Brazil: a biospectroscopic approach, RSC Adv. 6, 9964899655. doi.org/10.1039/C6RA21331F (2016).

21. Yao G, Zhang Y, Wang D, et al. GDM-Induced Macrosomia Is Reversed by Cav-1 via AMPK-Mediated Fatty Acid Transport and GLUT1-Mediated Glucose Transport in Placenta. PLoS One, 12(1):e0170490. doi:10.1371/journal.pone.0170490 (2017).

22. Hashemipour S, Haji Seidjavadi E, Maleki F, Esmailzadehha N, Movahed F, Yazdi Z. Level of maternal triglycerides is a predictor of fetal macrosomia in non-obese pregnant women with gestational diabetes mellitus. Pediatr Neonatol, 59(6):567-572. doi:10.1016/j.pedneo.2018.01.008 (2018).

23. Plows JF, Stanley JL, Baker PN, et al. The Pathophysiology of Gestational Diabetes Mellitus. Int J Mol Sci, 19(11):3342. doi:10.3390/ijms19113342 (2018).

24. Tabrizi R, Asemi Z, Lankarani KB, et al. Gestational diabetes mellitus in association with macrosomia in Iran: a meta-analysis. J Diabetes Metab Disord, 18(1):41-50. Published 2019 Feb 21. doi:10.1007/s40200-019-00388-0 (2019). 
25. Bawah AT, Seini MM, Abaka-Yawason A, Alidu H, Nanga S. Leptin, resistin and visfatin as useful predictors of gestational diabetes mellitus. Lipids Health Dis, 18(1):221. doi:10.1186/s12944-0191169-2 (2019).

26. Moyce BL, Dolinsky VW. Maternal $\beta$-Cell Adaptations in Pregnancy and Placental Signalling: Implications for Gestational Diabetes. Int J Mol Sci, 19(11):3467. doi:10.3390/ijms19113467 (2018).

27. Usta A, Usta CS, Yildiz A, et al. Frequency of fetal macrosomia and the associated risk factors in pregnancies without gestational diabetes mellitus. Pan Afr Med J, 26:62. doi:10.11604/pamj.2017.26.62.11440 (2017).

28. Martino J, Sebert S, Segura MT, et al. Maternal Body Weight and Gestational Diabetes Differentially Influence Placental and Pregnancy Outcomes. The Journal of Clinical Endocrinology \& Metabolism, Vol. 101, Issue 1, Pages 59-68. doi: doi.org/10.1210/jc.2015-2590 (2016).

29. Su W, Chen Y, Huang P, et al. Effects of Prepregnancy Body Mass Index, Weight Gain, and Gestational Diabetes Mellitus on Pregnancy Outcomes: A Population-Based Study in Xiamen, China, 2011-2018. Annals of Nutrition and Metabolism. Annals of Nutrition and Metabolism - Volume 75, Issue 1, pp. 31-38, (2019).

30. Zeng Z, Liu F, Li S. Metabolic Adaptations in Pregnancy: A Review. Ann Nutr Metab, 70(1):59-65. doi:10.1159/000459633 (2017).

\section{Figures}


(A)



Without GDM

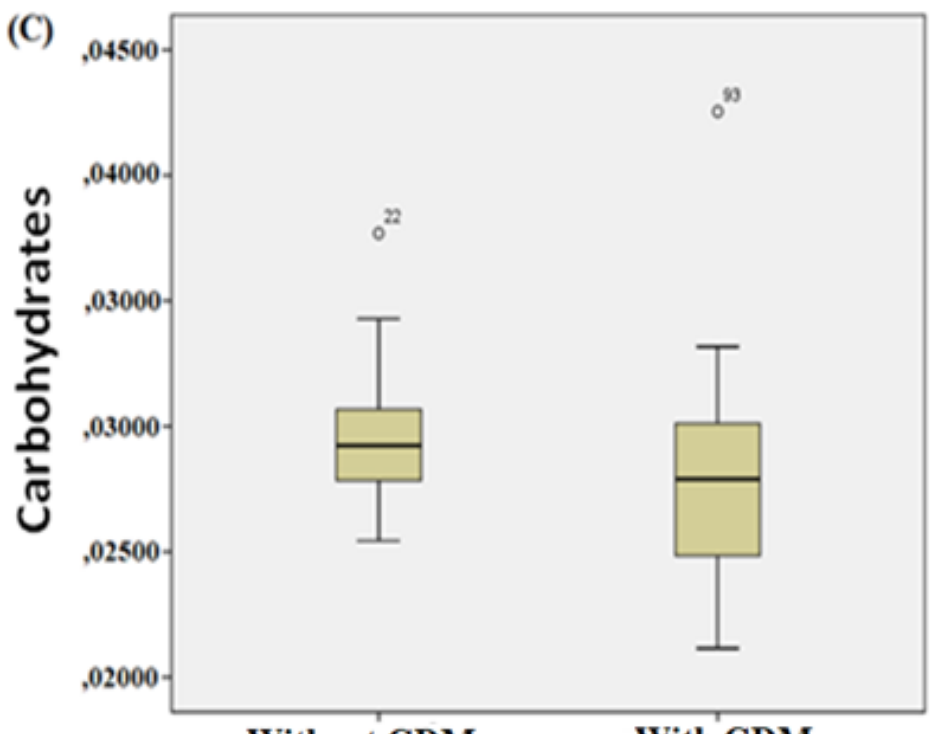

Without GDM

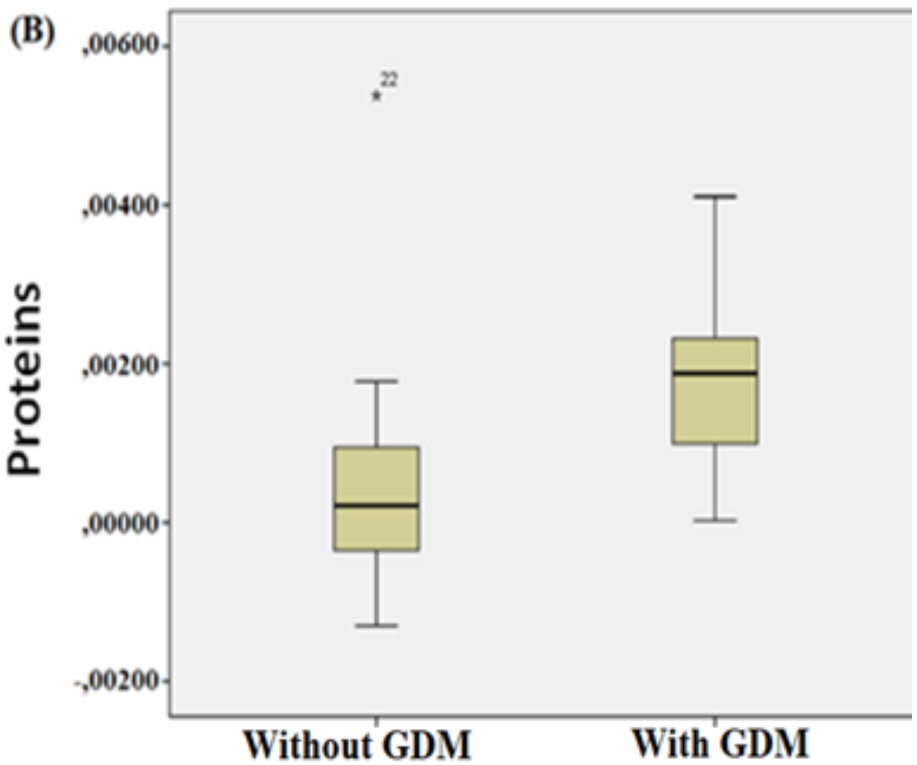

(D)

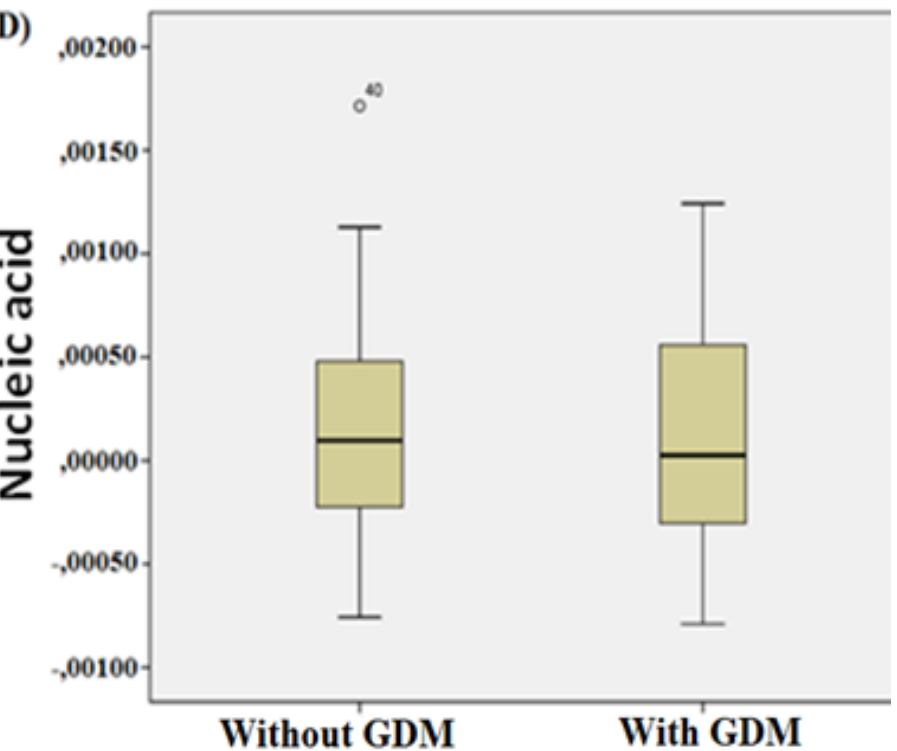

\section{Figure 1}

Distributions of the absorbances of biomolecules present in the blood plasma of mothers with and without GDM. 


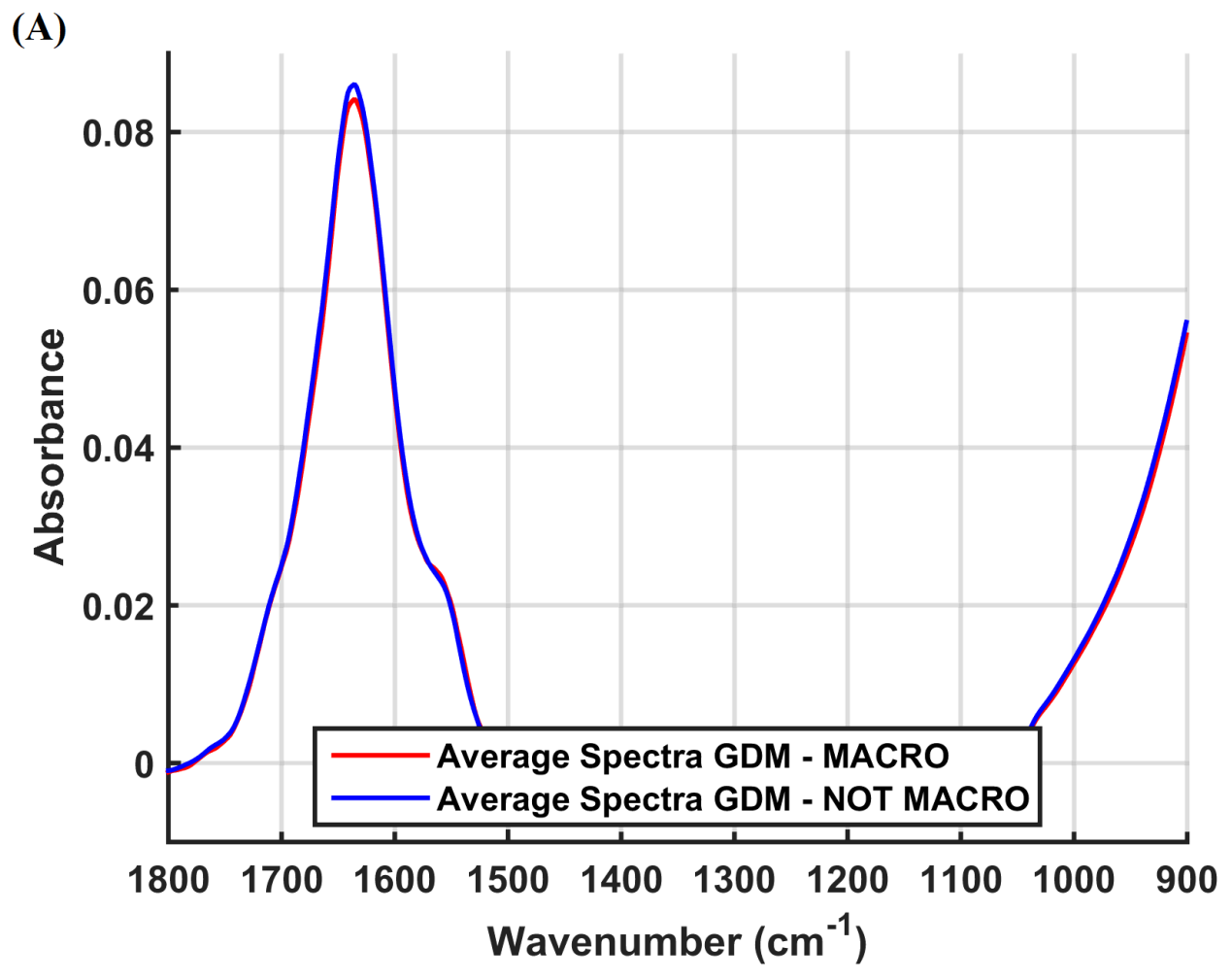

(B)

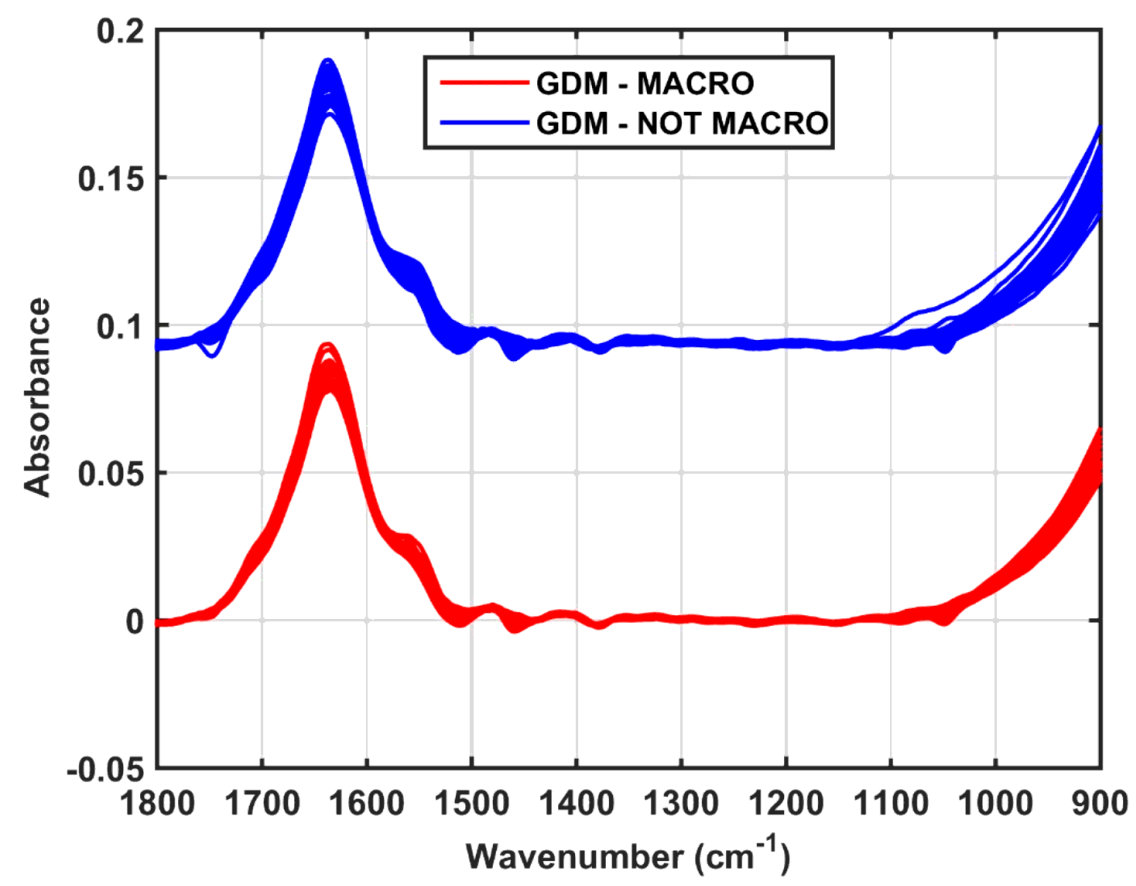

Figure 2

Decrease in protein absorbance in GDM mothers and association with macrosomia according to the regions in the spectrum. Processed spectra for both groups (A). Average spectrum of each processed group (B). 